\title{
IN VITRO EVALUATION OF THE EFFECT OF DIFFERENT IRRIGATION SOLUTIONS ON THE APICAL SEALING ABILITY OF THREE ROOT CANAL SEALERS WHEN THE CONTINUOUS WAVE OBTURATION TECHNIQUE WAS USED
}

\author{
Mohamed AM. El Sayed* and Shakeri M. Fathieh"**
}

\begin{abstract}
Aim: The aim of this study was to compare the effect of three irrigating solutions on the apical sealing ability of three endodontic sealers when the continuous wave obturation technique was used.

Materials and Methods: 100 maxillary central incisors were decoronated and roots were divided into three experimental groups ( $\mathrm{n}=30 \mathrm{each}$ ) according to the type of irrigating solution, and two control groups ( $\mathrm{n}=5$ each). Each experimental group was divided equally into three subgroups according to the type of obturation system. All canals were instrumented using ProTaper Universal rotary system and irrigated with 3\% sodium hypochlorite (Group 1), 2\% chlorohexidine (Group 2), and 3\% hydrogen peroxide (Group 3), followed by 17\% EDTA and distilled water. Continuous wave technique was used to obturate root canals with the following combinations: MTA Fillapex/ Gutta-percha (Subgroup A), AH Plus/Gutta-percha (Subgroup B) and Realseal SE/Realseal (Subgroup C). The apical microleakage was assessed using linear dye penetration method and the data were statistically analyzed.
\end{abstract}

Results: Significant differences were found between all groups $(\mathrm{P}<0.05)$. All root canal sealers after irrigation with $3 \%$ hydrogen peroxide showed the lowest amounts of apical leakage. Samples irrigated with $3 \%$ sodium hypochlorite or $2 \%$ chlorohexidine showed the highest amounts of apical leakage.

Conclusions: The type of irrigating solution could affect the apical sealing ability of experimental sealers when used with the continuous wave obturation technique. Root canal irrigation with 3\% hydrogen peroxide $+17 \%$ EDTA increased the sealing ability of all root canal sealers. Root canal irrigation with $3 \%$ sodium hypochlorite $2 \%$ chlorohexidine $+17 \%$ EDTA decreased the sealing ability of all root canal sealers.

KEY WORDS: AH Plus, continuous wave obturation technique, microleakage, MTA Fillapex, Realseal SE, root canal irrigants.

* Associate Professor, Endodontic Department, Faculty of Dentistry, Mansoura University, Mansoura, Egypt; Restorative Dentistry Department, College of Dentistry, Ajman University, Ajman, UAE.

** General Practitioner, Restorative Dentistry Department, College of Dentistry, Ajman University, Ajman, UAE 


\section{INTRODUCTION}

A successful root canal treatment necessitates proper cleaning, shaping, and obturation of the root canal system ${ }^{[1]}$. Total removal of the intracanal microorganisms after endodontic instrumentation cannot be achieved due to the anatomical variations of the root canal system ${ }^{[2]}$. Therefore, different types of chemical irrigants such as sodium hypochlorite $(\mathrm{NaOCl})$, chlorhexidine gluconate $(\mathrm{CHX})$ and hydrogen peroxide $\left(\mathrm{H}_{2} \mathrm{O}_{2}\right)$ have been used to reduce the bacterial load in the infected root canals ${ }^{[3-5]}$. These irrigating solutions are not able to remove the smear layer that is formed after the root canal instrumentation ${ }^{[5]}$. Therefore, $17 \%$ ethylenediaminetetraacetic acid (EDTA) was recommended to be used as the last irrigation solution to remove this layer and improve the quality of adhesion and sealing capacity of root canal sealers ${ }^{[5]}$. However, the irrigant solutions may cause chemical and structural changes in radicular dentin that could affect the adhesion of obturation materials, specially bonded materials, to dentin surface ${ }^{[6-8]}$.

It has been demonstrated that sodium hypochlorite solution, hydrogen peroxide solution, or a combination of both, cause deep changes in the collagen structure by dehydration and/or removal of fibrils that form the hybrid layer, thus reducing monomer penetration into dentin, and consequently bond strength of bondable root canal sealers ${ }^{[6]}$. Oxygen release from substances applied to the root canal could inhibit polymerization of methacrylatebased sealers ${ }^{[7]}$. On contrary, it has been also shown that the using of $\mathrm{CHX}$ could improve the integrity of the hybrid layer and resin-dentin bond stability ${ }^{[8]}$.

The root canal filling must seal the canal space both apically and coronally to reduce microleakage and entomb any inflammatory irritants such as microorganisms ${ }^{[9]}$. Gutta-percha is currently the most common material to fill root canals when used with an appropriate endodontic sealer ${ }^{[10]}$.
It possesses many favorable properties, which include biological compatibility, dimensional stability, pliability, easy placement and removal, and radiopacity, but does not bond to the root dentin walls ${ }^{[11]}$. The use of an endodontic sealer is essential to obtain a fluid-tight seal between the dentinal wall and the core obturation material ${ }^{[12]}$.

Resin based sealers such as AH Plus (Dentsply Maillefer, Ballaigues, Switzerland) are widely used because of its good physical and chemical properties and good sealing ability ${ }^{[13]}$. MTA Fillapex is a relatively new paste-paste MTA-based root canal sealer developed by Angelus (Londrina, Parana/ Brazil) and can promote cementum regeneration and provide perfect sealing ability, according to the manufacturer ${ }^{[14]}$. Reaseal SE (SybronEndo, CA, USA) is a dual cured self-etching methacrylate based sealer that can be used easily and bonds to both the Resilon core and radicular dentin through hybrid layers on both substrates leading to a monoblock unit, which may prevent leakage and improve the root strength ${ }^{[15,16]}$. The form and handling properties of Resilon (RealSeal) are similar to gutta-percha ${ }^{[17]}$.

Warm vertical compaction is a commonly used obturation technique, which promotes plasticization of gutta-percha to provide homogeneity of the obturating mass and better adaptation to the root canal walls ${ }^{[18]}$. To obtain an effective vertical compaction of gutta-percha or Resilon, Buchanan introduced the continuous wave vertical condensation technique ${ }^{[19]}$.

Most of endodontic failures are caused by the microleakage resulting from incomplete obturation ${ }^{[1]}$. Therefore, leakage tests are important in evaluating the excellence of the endodontic treatment. Passive dye penetration method is the most widely used because of its sensitivity, ease of use and convenience ${ }^{[20]}$.

The purpose of this study was to evaluate the influence of 3\% sodium hypochlorite, $2 \%$ chlorhexidine and $3 \%$ hydrogen peroxide on the apical sealing ability of MTA Fillapex, AH Plus, 
and Realseal SE/Resilon, when the continuous wave obturation technique was used. The null hypothesis of the current study was the sealing ability of root canal sealers will not be affected by the type of irrigation solution.

\section{MATERIALS AND METHODS}

\section{Samples grouping (Figure 1)}

One hundred extracted human maxillary central incisors with sound roots were used and randomly divided into three study groups of 30 samples each, according the type of irrigating solution, and 2 control groups of 5 teeth each. Each study group was further divided into three subgroups of 10 samples each according to the type of root canal sealer.

\section{Root canal preparation}

The crowns of selected teeth were sectioned so that the length of roots was standardized at 14 $\mathrm{mm}$. The root canals were accessed and the pulp tissues were removed using a barbed broach. The size of the initial file for selected samples was equal to or less than \#25 K-file. The working length was established by placing \#15 K-file (Dentsply, Maillefer, Ballaigues, Switzerland) into the root canal until it was visible at the apical foramen, and then $1 \mathrm{~mm}$ was subtracted from that length. The accuracy of the working length was confirmed radiographically. The canals were instrumented with ProTaper Universal NiTi rotary files (Dentsply Maillefer, Ballaigues, Switzerland) to size F4 following the manufacturer instructions. EDTA gel (TG Chelcream, UK) was used as a lubricant during root canal preparation.

Between files, root canals were irrigated with 5 $\mathrm{ml}$ of the following experimental irrigating solutions: $3 \%$ sodium hypochlorite (Group 1), 2\% chlorohexidine (Group 2), and 3\% hydrogen peroxide (Group 3). Finally, all samples were irrigated with $5 \mathrm{ml}$ of $17 \%$ EDTA solution (MD-Cleanser, META BIOMED Co. Ltd, Korea) for 1 minute, followed by $5 \mathrm{ml}$ distilled water. The irrigation was performed using a 27-gauge Max-i-Probe needle (Dentsply Maillefer, Ballaigues, Switzerland), which was inserted as deep as possible into the canal without binding. Apical patency was confirmed by inserting a size $10 \mathrm{k}$-file through the apical foramen before and after the root canal preparation. All prepared samples were kept moist in distilled water until the time for root canal obturation.

\section{Nail varnish application}

A size \#10 finger spreader (Mani Inc., TocigiKen, JA) was inserted from the external root surface through the apical foramen into the prepared root canal of each sample in the experimental and

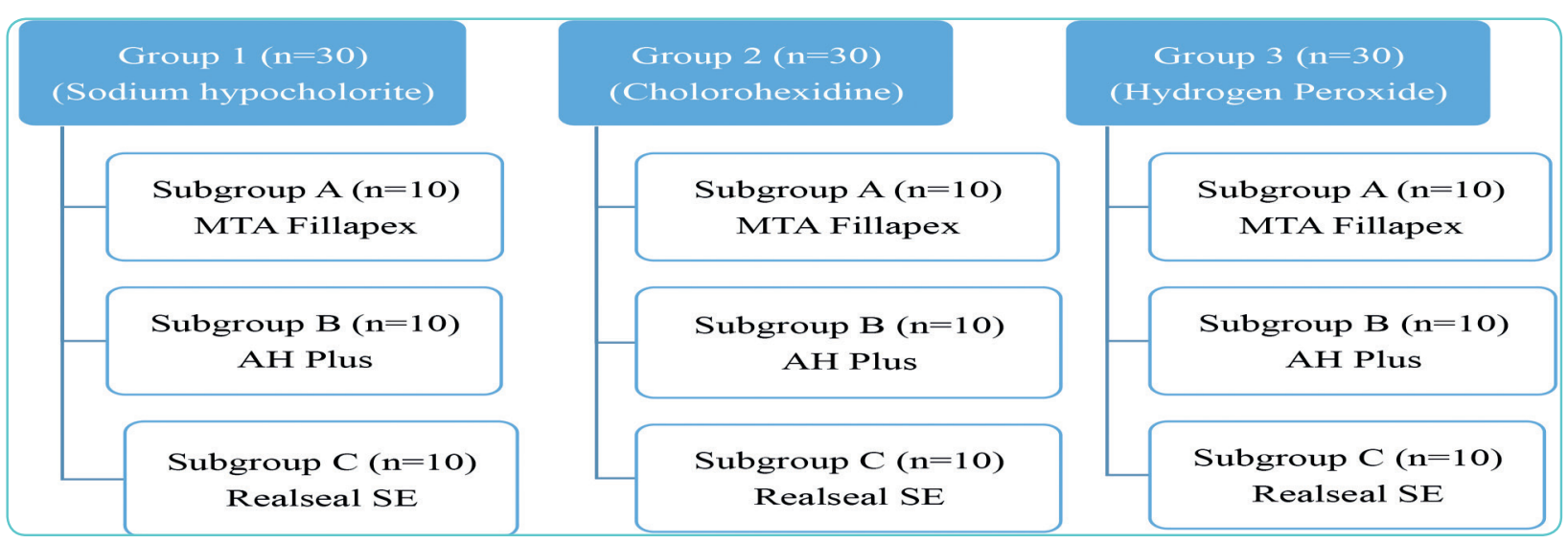

Fig. (1) Schematic diagram showing different experimental groups and subgroups. 
positive control groups. With the exception of the coronal surface and apical foramen, all external surfaces of roots were coated with three layers of nail varnish. Each layer was left to dry before applying the next layer of varnish. After complete setting of the varnish, the spreader was gently removed, keeping the apical foramens open. In the negative control group, all root surfaces were coated with nail varnish as in the experimental groups but including the apical foramen.

\section{Root canal obturation}

Continuous wave obturation technique was used to condense the following root canal filling combinations: MTA Fillapex/Protaper guttapercha size F4 (Subgroup A), AH Plus/ ProTaper gutta-percha size F4 (Subgroup B) and Realseal SE/Reaseal point size 40/0.06 (Subgroup C). The master cone was accepted if a tug back sensation was felt. If the cone was loose, it was trimmed with scissors. Samples in the negative control group did not receive root canal fillings, while in the positive control group; they were obturated with guttapercha but without sealer using continuous wave obturation technique.

The continues wave obturation was performed using Elements free system (Kerr Corporation 1717 West Collins Orange, CA, USA) for down filling of gutta-percha and Realseal and backfilling of guttapercha. Obtura III (Obtura Spartan, 175 Earth City, Missouri, US) was used for backfilling of Realseal using Realseal pellets. The canals were dried using F4 paper points (Dentsply Maillefer, Ballaigues, Switzerland). All sealers were mixed according to the manufacturer instructions and placed into root canals using a \#30 Lentulo spiral rotated at 300 $\mathrm{rpm}$ and $3 \mathrm{~mm}$ away from the apex. The tip of prefitted master cone was coated with a thin layer of its respected sealer and inserted into the canal to its full working length using up and down slow pumping motion. Elements free Downpacke was set at $200^{\circ} \mathrm{C}$ for gutta-percha vertical compaction (Subgroups A and $\mathrm{B}$ ), and at $150^{\circ} \mathrm{C}$ for Reaseal points (Subgroup
C). A Buchanan heat plugger (Fine-medium size) that fixed to Elements free Downpack was inserted along the master cone to $5 \mathrm{~mm}$ short of the working length. Heat application was then stopped and light apical pressure was retained for 10 seconds to counteract the shrinkage of core material. Then the plugger was withdrawn after application of a short heat burst. Elements free Backfill with Elements gutta-percha cartridge $\left(200^{\circ} \mathrm{C}\right)$ was used for backfilling of gutta-percha, while Obtura III device $\left(150^{\circ} \mathrm{C}\right)$ was used for backfilling of Realseal Pellets using a 23-gauge needle tip. The coronal surface of the roots obturated with Realseal was light cured for 40 seconds.

The quality of obturation was assessed radiographically, and samples with insufficient obturation were excluded from the study and replaced with new ones. All canal orifices of all samples were sealed with light-cured glass ionomer cement and then coated with two layers of nail varnish. All samples were incubated for 1 week at $37^{\circ} \mathrm{C}$ with $100 \%$ humidity to allow complete setting of sealers.

\section{Microleakage assessment}

Samples were placed in $2 \%$ methylene blue dye and stored at $37^{\circ} \mathrm{C}$ for 72 hours, after which they were thoroughly rinsed under running tap water. The nail varnish was gently removed with a scalpel blade no. 11. The apical $7 \mathrm{~mm}$ of each root was longitudinally sectioned in a buccolingual direction, and then a horizontal cut was made on the mesial or distal surface using a flexible diamond disc under water coolant. The $7 \mathrm{~mm}$ proximal portion of each sample was then separated and the filling material was removed using an endodontic explorer to allow better evaluation of dye penetration.

Microleakage in each sample was evaluated under a digital stereomicroscope (Leica EZ4W, Germany) at $20 \mathrm{X}$ magnification. Pictures were captured, saved, and the maximum apical dye penetration leakage was measured using ImageJ software (National Institutes of Health, Bethesda, MD, USA) (Figure 2). In order to eliminate the 
operator variable, a single operator completed all preparations and testing procedures.

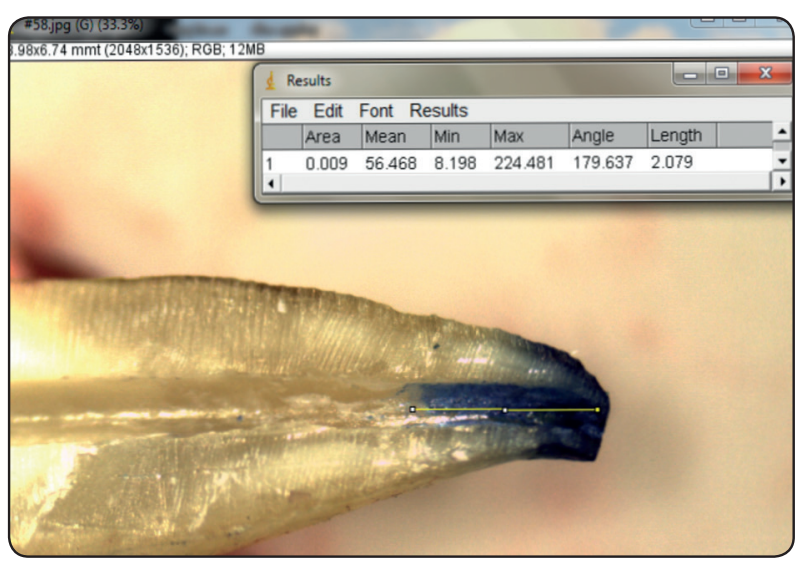

Fig. (2) Measurement of linear apical leakage using ImageJ software.

\section{Statistical analysis}

The statistical analysis was performed using IBM SPSS version 20 (IBM Corporation 1 New Orchard Road Armonk, New York 10504-1722, United States). Data normality and homogeneity were assessed by Kolmogorov-Smirnov normality test and Levene's test, respectively. One-Way ANOVA test was selected to compare the mean values of dye penetration in all groups and subgroups. Pairwise comparisons of dye penetration in various groups and subgroups were carried out by Tukey's or Games-Howell's Post hoc tests depending on the results of Levene's test. All the level of statistical significance was set at a $\mathrm{P}<0.05$.

\section{RESULTS}

The mean values and standard deviations of the apical dye leakage in all groups are presented in Table 1 and illustrated in Figure 3. All experimental groups including their subgroups demonstrated apical dye leakage of variable degrees (Figure 4). The positive control group showed the maximum amount of dye penetration whilst the negative control group showed no evidence of dye penetration.

ANOVA test showed significant differences $(P<0.05)$ between irrigating solutions (Groups) regarding their effect on the sealing ability of root canal sealers [Table 1]. Samples irrigated with 3\% $\mathrm{H}_{2} \mathrm{O}_{2}+17 \%$ EDTA (Group 1) showed the lowest significant amount of leakage; while samples irrigated with $3 \% \mathrm{NaOCl}$ or $2 \% \mathrm{CHX}+17 \%$ EDTA

TABLE (1) Mean values of apical dye leakage ( $\mathrm{mm}$ ) in root canals filled with warm vertically compacted obturation systems after using different irrigating solutions.

\begin{tabular}{|c|c|c|c|c|}
\hline \multirow{3}{*}{$\begin{array}{c}\text { Groups } \\
\text { (Irrigation solutions) }\end{array}$} & \multicolumn{4}{|c|}{ Apical linear dye penetration (Mean \pm Stander deviation in $\mathrm{mm}$ ) } \\
\hline & \multicolumn{4}{|c|}{ Subgroups (Root canal sealers) } \\
\hline & $\begin{array}{c}\text { Subgroup A } \\
\left(\text { MTA Fillapex } / G P^{\circ}\right)\end{array}$ & $\begin{array}{l}\text { Subgroup B } \\
(A H P l u s / G P)\end{array}$ & $\begin{array}{c}\text { Subgroup C } \\
\text { (Realseal SE/Realseal) }\end{array}$ & $\begin{array}{l}\text { ANOVA } \\
(P \text { value })\end{array}$ \\
\hline $\begin{array}{c}\text { Group } 1 \\
\text { (Sodium hypochlorite) }\end{array}$ & $2.43 \pm .0 .84^{\mathrm{A}^{*}}$ & $2.30 \pm 0.26^{\mathrm{A}}$ & $2.11 \pm 0.25^{\mathrm{A}}$ & 0.414 \\
\hline $\begin{array}{c}\text { Group } 2 \\
\text { (Chlorohexidine) }\end{array}$ & $2.66 \pm 0.91^{\mathrm{A}}$ & $2.44 \pm 0.52^{\mathrm{A}}$ & $2.66 \pm 0.45^{\mathrm{A}}$ & 0.701 \\
\hline $\begin{array}{c}\text { Group } 3 \\
\text { (Hydrogen peroxide) }\end{array}$ & $1.40 \pm 0.22^{\text {в }}$ & $1.44 \pm 0.83^{\text {в }}$ & $1.30 \pm 0.82^{\text {в }}$ & 0.898 \\
\hline ANOVA ( $P$ value $)$ & $\begin{array}{c}0.001 \\
\text { (Games-Howell test) }\end{array}$ & $\begin{array}{c}0.012 \\
\text { (Games-Howell test) }\end{array}$ & $\begin{array}{c}0.000 \\
\text { (Tukey test) }\end{array}$ & \\
\hline
\end{tabular}

${ }^{\circ}$ GP $=$ Gutta-percha

*Means with the different superscript letters in each column (Groups) or raw (Subgroups) had significant difference $(P<0.05)$. 
(Groups 1 and 2) showed the highest amount of leakage for all experimental sealers

When the microleakage mean values of root canal sealers within each group were compared, no significant differences were observed among them $(P>0.05)$. Two-way ANOVA test (Table 2) confirmed the previous results and showed that the type of irrigating solution affected significantly the apical seal of all experimental roots canal sealers.

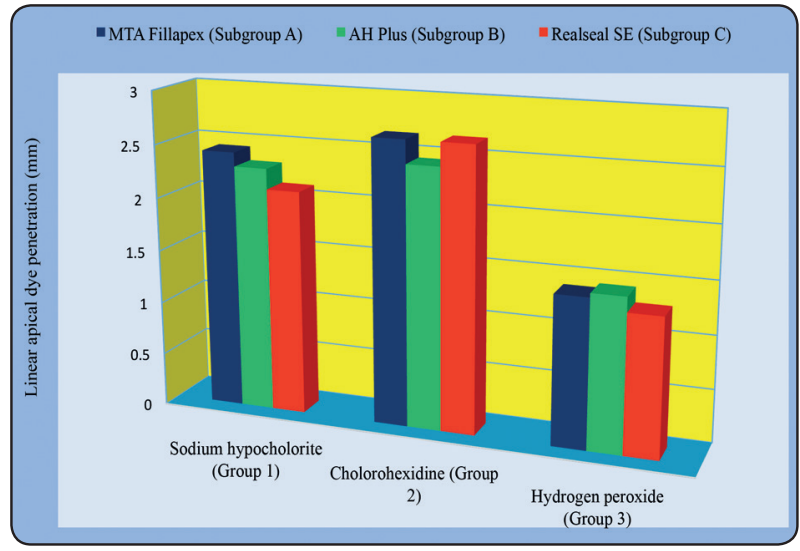

Fig. (3) Effect of irrigating solutions on sealing ability of different root canal sealers when used with continuous wave obturation technique.

TABLE (2) Statistical results of Univariate Analysis of Variance (Two-Way ANOVA) that determine the effect of different irrigating solutions and root canal sealers on the apical leakage of experimental samples.

\begin{tabular}{|c|c|c|c|c|c|}
\hline Source & Sun of Squares & df & Mean Square & F & Sig. \\
\hline Type of irrigating solution (X1) & 23.70 & 2 & 11.85 & 29.95 & 0.000 \\
\hline Type of root canal sealers (X2) & 0.319 & 2 & 0.16 & 0.403 & 0.669 \\
\hline Irrigation type * Sealers & 0.610 & 4 & 0.153 & 0.39 & 0.818 \\
\hline Error & 32.05 & 81 & 0.396 & & \\
\cline { 1 - 3 } & 447.63 & 90 & & \\
\hline
\end{tabular}

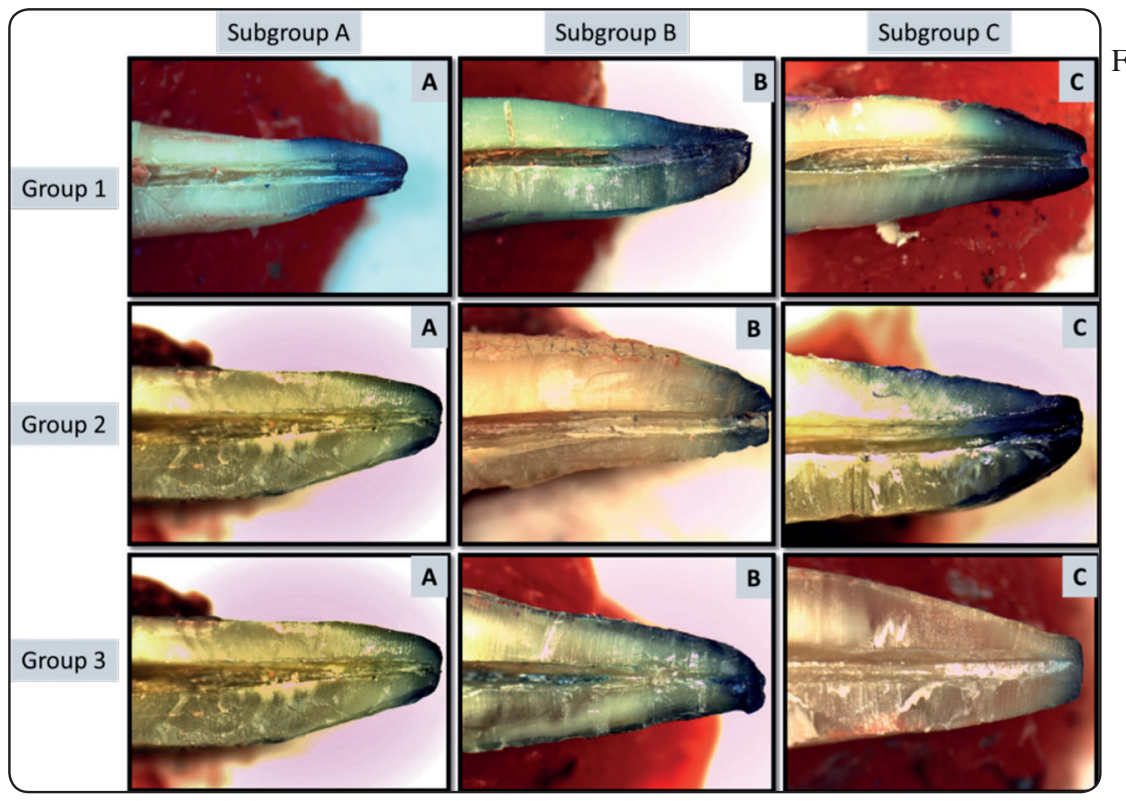

Fig. (4) Apical dye leakage of selected samples filled with the continuous wave obturtion technique after using different irrigating solutions for all groups and subgroups*.

* Group 1 (Sodium hypochlorite); Group 2 (Chlorohexidine); Group 3 (Hydrogen peroxide); Subgroup A (MTA Fillapex); Subgroup B (AH Plus); Subgroup C (Realseal SE). 


\section{DISCUSSION}

The development and maintenance of threedimensional sealing of the root canal system is the key of successful root canal treatment. To obtain a hermetic apical seal, different obturation materials and techniques were introduced and evaluated. The development of new types of obturation systems may solve the problem of microleakage associated with currently used materials.

The sealing ability of any obturation technique depends on the quality of root canal sealer ${ }^{[7]}$. In the current study, three types of well-known root canal sealers were used: MTA Fillapex, AH Plus, and Realseal SE. AH Plus is considered the gold standard to which other types of root canal sealers are compared because it has good physical and chemical properties as well as good sealing ability ${ }^{[13]}$. The Realseal SE is a self-etching methacrylate based sealer which was claimed to produce monoblock unit with radicular dentin, prevent leakage and improve the root strength ${ }^{[16]}$. MTA Fillapex is a new MTA-based sealer, which has excellent biocompatibility, bioactivity, osteoconductivity, and perfect seal ${ }^{[14]}$.

Root canal irrigation solutions may cause alteration in chemical and structural composition of radicular dentin. Thereby changing its permeability and solubility characteristics and hence affecting the adhesion of materials to dentin surfaces ${ }^{[21]}$. Therefore, the aim of the current study was to study the effect of $3 \% \mathrm{NaOCl}, 2 \% \mathrm{CHX}$ and $3 \% \mathrm{H}_{2} \mathrm{O}_{2}$ as irrigating solutions on the apical sealing ability of three root canal sealers when continuous wave obturation technique was used.

Using extracted human teeth in the current study introduced variabilities, which closely simulate the clinical situations. Extracted maxillary central incisors with nearly similar apical diameters and root lengths were selected and instrumented to \#F4 ProTaper Universal nickel titanium rotary instrument. Therefore, variables such as anatomical variation, canal size and the diameter of the apical foramen, which can affect the apical leakage, were minimized. Moreover, the rotary instrumentation was found to be less time consuming, more comfortable, more efficient than hand instrumentation ${ }^{[22]}$.

During instrumentation, samples in each group were irrigated only with one of the experimental irrigation solution, and the last irrigant was always $17 \%$ EDTA to remove smear layer ${ }^{[5,23]}$, which was followed by distilled water to remove any traces of previous irrigation solutions. This protocol allowed evaluating the effect of one irrigant type on the sealing ability of the particular root canal sealer.

Methylene blue dye penetration method was used in the current study to evaluate the apical microleakage because it is inexpensive, reliable method and easy to manipulate ${ }^{[20]}$. In addition, it has a high degree of staining ability and a molecular weight lower than that of bacterial toxins ${ }^{[24]}$. The root canal filling material that does not permit penetration of small molecules, such as dyes, has the ability to prevent leakage of larger molecules, such as bacteria and their byproducts ${ }^{[24]}$. A 72-hours immersion period was used in the present study, as the experimental protocol did not include an additional active penetration device such as a vacuum. It has been reported that elimination of air may induce an overestimated results of the in vivo extent of microleakage ${ }^{[14]}$.

In the current study continuous wave vertical condensation technique was used, as it can reduce void formation, provide good adaptation of root filling material to the root canal walls and fill certain hard-to-reach areas of the root canal system $^{[18]}$.

The experimental design in the present study was assessed by using positive and negative control groups. The positive control group indicated that leakage testing was a suitable method for maximum dye penetration without a sealer. The negative control group showed no dye penetration indicating 
the using of three layers of varnish is effective to prevent dye penetration through root surfaces and apical foramen ${ }^{[26]}$.

The results of previous studies showed no significant differences between Epiphany/Resilon and $\mathrm{AH}$ plus/gutta-percha root canal filling materials in terms of the apical sealing ability when the root canals were irrigated with $\mathrm{NaOCl}{ }^{[27-29]}$. The findings of the current study are consistent with these studies in spite of different obturation technique and leakage assessment method. Moreover, the current results showed no statistical significant difference between root canal sealers when their apical leakage mean values were compared after using each irrigant solution. However, some authors showed that MTA Fillapex resulted in more microleakage than $\mathrm{AH}$ Plus ${ }^{[9,20]}$.

In general, samples irrigated with $\mathrm{NaOCl}$ and CHX solutions showed high leakage values, while samples irrigated with hydrogen peroxide showed low leakage values, regardless the type of root canal sealer. $\mathrm{NaOCl}$ has been shown to damage the organic components of dentin, mainly through collagen dissolution, and can hinder the formation of a consistent hybrid layer ${ }^{[7]}$. Furthermore, $\mathrm{NaOCl}$ breaks down into sodium chloride and oxygen, which can interfere with resin sealer polymerization which reduce bond strength with radicular dentin ${ }^{[30]}$.

In spite of $\mathrm{CHX}$ has the ability to increases the wettability of endodontic sealers on dentin ${ }^{[31]}$, the results of present study are matching with the results of Bodrumlu et al. who showed that that the apical sealing ability of AH plus, Epiphany SE root canal sealers decreased when the chlorhexidine was used as an irrigation solution ${ }^{[32]}$. This may be attributed to inability of CHX to dissolve organic tissues from the root canal system, ant its bonding to dentin surface which may prevent the adhesion of the sealer to the root canal walls ${ }^{[33]}$.

Nikhil et al. ${ }^{[34]}$ compared the depth of penetration of MTA Fillapex and AH Plus sealers into the dentinal tubules with the use of a confocal laser microscope and reported that MTA Fillapex sealer penetrated deeper into the dentinal tubules. However, studies by Sönmez et al. ${ }^{[14]}$ and Ferreira et al . ${ }^{[29]}$ showed that MTA Fillapex resulted in more microleakage than AH Plus when irrigating the canals with $\mathrm{NaOCl}$ and EDTA. These results are contrary to the current results that showed both materials have similar high leakage values. This may be attributed to the temperature used with continuous wave obturation technique that may increase the amount of apical leakage by decreasing the setting time of experimental sealers, consequently decrease their penetration ability (Flow) into the dentinal tubules, and increase leakage ${ }^{[35]}$. Moreover, some authors have shown that EDTA negatively interferes with the hydration of MTA ${ }^{[36]}$.

In addition, the heat generation during warm vertical compaction, which accelerate the setting of the sealers, may prevent the relief of polymerization stresses by slow flow of methacrylate-based sealer ${ }^{[37,38]}$. Based on the manufacturer's instruction, an immediate light curing of the coronal part of Resilon system will create a coronal seal but may also limit flow of resin sealer ${ }^{[39]}$. In addition, manipulation of the partially polymerized methacrylate resin based sealer during compaction of the root filling materials might disrupt the developing bonds between a self-etching sealer and radicular dentin ${ }^{[40]}$.

Marshall et al. observed a small increase of the dentin permeability to radioisotopes when the root canals were irrigated with $5.25 \% \mathrm{NaOCl}{ }^{[41]}$. However, the association of this solution with $3 \%$ hydrogen peroxide solution significantly increased the dentin permeability.

The use of hydrogen peroxide during canal instrumentation effectively removes remnants of pulp tissue and dentin debris. However, its use could affect negatively the bond strength of resin cement to root canal dentin ${ }^{[42,43]}$. Hydrogen peroxide breaks down to water and oxygen thus inducing liberation of oxygen by the chemical reaction of hydrogen 
peroxide with sodium hypochlorite. Oxygen from such chemicals causes strong inhibition of the interfacial polymerization of resin bonding material ${ }^{[43]}$. This may increase the setting time of the sealer and counteract the effect of raising temperature during continuous wave obturation technique that decrease setting time of sealer. This could allow more sealer penetration into dentinal tubules and hence improve sealing ability of resinbased sealer. Bojar et al. ${ }^{[44]}$ showed that ozone therapy improved shear bond strength of two root canal sealers (AH-26 and EX Fill). A similar effect may be obtained with the use of $3 \%$ hydrogen peroxide irrigation.

RealSeal manufacturer's instructions recommend EDTA or CHX as final irrigant solutions followed by sterile water flushing as $\mathrm{NaOCl}$ and hydrogen peroxide may damage dentine wall adhesion. The final use of EDTA eliminates the smear layer and exposes the collagen fibers thus increasing the hydrophilicity of the dentine surface, which favors the hybridization of hydrophilic material such as methacrylate-based sealers ${ }^{[45]}$. Therefore, reduced leakage is caused by greater micromechanical interactions amongst the adhesive agents, the collagen matrix, and the mineralized base of the intertubular dentine ${ }^{[38]}$.

Vilanova et al. reported that with $1 \% \mathrm{NaOCl}$, followed by a final 17\% EDTA irrigation, greater adhesive strength was obtained between Epiphany and the root canal walls ${ }^{[46]}$. A number of studies have observed that a final flush with CHX does not negatively affect bond strength ${ }^{[47]}$. Ozturk \& Özer reported that the use of $\mathrm{NaOCl}$ produced a significant decrease in bond strength with the dentine walls ${ }^{[7]}$. In a similar manner, Vilanova et al. observed that $1 \% \mathrm{NaOCl}$ as final irrigant produced weaker adhesion ${ }^{[46]}$.

The null hypothesis of the current research was rejected as the results indicated that the sealing ability of the experimental root canal sealers were significantly affected by the type of irrigating solutions.
The use of hydrogen peroxide as an irrigation solution should be revaluated regarding its effect on the sealing ability of the available root canals sealers and also its effect on the radicular dentin structure.

\section{CONCLUSIONS}

Within the limitations of the current study, the following conclusions could be drawn:

1. The type of irrigating solution affected significantly the apical sealing ability of experimental sealers when used with the continuous wave obturation technique.

2. The sealing ability of root canal sealers increased when the root canals were irrigated with $3 \%$ hydrogen peroxide $+17 \%$ EDTA solution.

3. The sealing ability of root canal sealers decreased when the root canals were irrigated with $3 \%$ sodium hypochlorite or $2 \%$ chlorohexidine + $17 \%$ EDTA.

4. The apical sealing ability of tested root canal sealers was statistically similar after using each irrigant solution.

\section{REFERENCES}

1. Nair PN. Pathogenesis of apical periodontitis and the causes of endodontic failures. Crit Rev Oral Biol Med 2004; 15: 348-381.

2. Gu LS, Kim JR, Ling J, Choi KK, Pashley DH, Tay FR. Review of contemporary irrigant agitation techniques and devices. J Endod 2009; 35: 791-804.

3. Mohammadi Z. Sodium hypochlorite in endodontics: an update review. Int Dent J 2008; 58: 329-341.

4. Basrani B, Lemonie C. Chlorhexidine gluconate. Aust Endod J 2005; 3: 48-52.

5. Haapasalo $\mathbf{M}$, Shen $\mathrm{Y}$, Qian $\mathrm{W}$, Gao $\mathrm{Y}$. Irrigation in endodontics. Dent Clin North Am 2010; 54:291-312.

6. Torneck CD, Titley KC, Smith DC, Adibfar A. The influence of time of hydrogen peroxide exposure on the adhesion of composite resin to bleached bovine enamel. J Endod 1990; 16:123-128. 
7. Ozturk B, Özer F. Effect of $\mathrm{NaOCl}$ on bond strengths of bonding agents to pulp chamber lateral walls. J Endod 2004;30:362-365

8. Carrilho MR, Geraldeli S, Tay F, de Goes MF, Carvalho RM, Tjäderhane L, Reis AF, Hebling J, Mazzoni A, Breschi L, Pashley D. In vivo preservation of the hybrid layer by chlorhexidine. J Dent Res. 2007; 86:529-533.

9. Sundqvist G, Figdor D. Endodontic treatment of apical periodontitis. In: Orstavik D, Pitt Ford TR, eds. Essential endodontology: prevention and treatment of apical periodontitis, Oxford: Blackwell Science Ltd, 1998:253.

10. Walton RE, Torabinejad M. Principles and practice of endodontics. 3rd ed. Philadelphia: WB Saunders, 2002:246.

11. Hauman $\mathrm{CH}$, Love RM. Biocompatibility of dental materials used in contemporary endodontic therapy: a review. Part 2. Root-canal-filling materials. Int Endod J. 2003;36:147-160.

12. Orstavik D, Kerekes K, Eriksen HM. Clinical performance of three endodontic sealers. Endod Dent Traumatol 1987; 3:178-186.

13. Sevimay S, Kalayci A. Evaluation of apical sealing ability and adaptation to dentine of two resin-based sealers. J Oral Rehabil. 2005; 32:105-110.

14. Sonmez I, Oba A, Sonmez D, Almaz M. In vitro evaluation of apical microleakage of a new MTA-based sealer. Eur Arch Paediatr Dent 2012; 5:252-255.

15. Shipper G, Orstavik D, Teixeira FB, Trope M. An evaluation of microbial leakage in roots filled with a thermoplastic synthetic polymer-based root canal filling material (Resilon). J Endod 2004;30:342-347.

16. Babb BR, Loushine RJ, Bryan TE, Ames JM, Causey MS, Kim J, Kim YK, Weller RN, Pashley DH, Tay FR. Bonding of self-adhesive (self-etching) root canal sealers to radicular dentin. J Endod 2009; 35:578-582.

17. Miner MR, Berzins DW, Bahcall JK. A comparison of thermal properties between gutta-percha and a synthetic polymer based root canal filling material (Resilon). J Endod 2006; 32:683-686.

18. Schilder H. Filling root canal in three dimensions. Dent Clin North Am 1967; 11:723-744.

19. Buchanan LS. The continuous wave of obturation technique: 'centered' condensation of warm gutta percha in 12 seconds. Dent Today. 1996; 15: 60-62, 64-67.
20. Veríssimo DM, do Vale MS. Methodologies for assessment of apical and coronal leakage of endodontic filling materials: a critical review. J Oral Sci 2006 ;48:93-98

21. Dogan H, Oalt S. Effects of chelating agents and sodium hypochlorite on mineral content of root dentin. J Endod 2001; 27:578-580.

22. Aguiar CM, Mendes DA, Câmara AC, Figueiredo JAP. Assessment of canal walls after biomechanical preparation of root canals instrumented with Protaper Universal ${ }^{\mathrm{TM}}$ rotary system. J Appl Oral Sci 2009; 17:590-595.

23. Economides N, Liolios E, Kolokuris I, Beltes P. Long term evaluation of the influence of smear layer removal on the sealing ability of different sealers. J Endod. 1999; 25:123-125.

24. Oliver CM, Abbott PV. Correlation between clinical success and apical dye penetration. Int Endod J 2001; 34:637-644.

25. Kubo CH, Gomes AP, Mancini MN. In vitro evaluation of apical sealing in root apex treated with demineralization agents and retrofilled with mineral trioxide aggregate through marginal dye leakage. Braz Dent J. 2005; 16:187-191

26. Haïkel Y, Wittenmeyer W, Bateman G, Bentaleb A, Allemann C. A new method for the quantitative analysis of endodontic microleakage. J Endod. 1999; 25:172-177.

27. Raina R, Loushine RJ, Weller RN, Tay FR, Pashley DH. Evaluation of the quality of the apical seal in Resilon/ Epiphany and Gutta-Percha/AH Plus-filled root canals by using a fluid filtration approach. J Endod. 2007; 33:944-947.

28. Paqué F, Sirtes G. Apical sealing ability of Resilon/ Epiphany versus gutta-percha/AH Plus: immediate and 16-months leakage. Int Endod J. 2007;40:722-729.

29. Ferreira M, Abrantes M, Ferreira H, Carrilho E, Botelho M. Comparison of the apical seal on filled root canals with Topseal vs MTA Fillapex sealers: A quantitative scinti-graphic analysis. Open Journal of Stomatology 2013; 3: 128-132.

30. Souza SFC, Bombana AC, Francci C, Gonçalves F, Castellan C, Braga RR. Polymerization stress, flow and dentine bond strength of two resin-based root canal sealers. Int Endod J. 2009; 42:867-873.

31. Assis DF, Prado M, Simão RA. Evaluation of the interaction between endodontic sealers and dentin treated with different irrigant solutions. J Endod. 2011;37:1550-1552. 
32. Bodrumlu E, Parlak E, Bodrumlu EH. The effect of irrigation solutions on the apical sealing ability in different root canal sealers. Braz Oral Res. 2010; 24:165-169.

33. Carvalho AS, Camargo CH, Valera MC, Camargo SE, Mancini MN. Smear layer removal by auxiliary chemical substances in biomechanical preparation: a scanning electron microscope study. J Endod. 2008;34:1396-400.

34. Nikhil V, Bansal P, Sawani S. Effect of technique of sealer agitation on percentage and depth of MTA Fillapex sealer penetration: A comparative in-vitro study. J Conserv Dent. 2015;18:119-123.

35. Qu W, Bai W, Liang YH, Gao XJ. Influence of warm vertical compaction technique on physical properties of root canal sealers. J Endod. 2016;42:1829-1833.

36. Rawtiya M, Verma K, Singh S, Munuga S, Khan S. MTABased root canal sealers. J Orofac Res 2013; 3: 16-21.

37. Lawson MS, Loushine B, Mai S, Weller RN, Pashley DH, Tay FR, Loushine RJ. Resistance of a 4-META-containing, methacrylate-based sealer to dislocation in root canals. J Endod 2008; 34:833-837.

38. Fisher MA, Berzins DW, Bahcall JK. An in vitro comparison of bond strength of various obturation materials to root canal dentin using a push-out test design. J Endod 2007;33:856-858.

39. Braga RR, Ferracane JL, Condon JR. Polymerization contraction stress in dual-cure cements and its effect on interfacial integrity of bonded inlays. J Dent 2002;30: 333-340.

40. Tay FR, Loushine RJ, Weller RN, Kimbrough WF, Pashley DH, Mak YF, Lai CN, Raina R, Williams MC.
Ultrastructural evaluation of the apical seal in roots filled with a polycaprolactone-based root canal filling material. J Endod 2005;31:514-519.

41. Marshall FJ, Massler M, Dute HL. Effects of endodontic treatments on permeability of root dentine. Oral Surg Oral Med Oral Pathol. 1960;13:208-223.

42. Erdemir A, Eldeniz AU, Belli S, Pashley DH. Effect of solvents on bonding to root canal dentin. J Endod. 2004;30:589-592.

43. Nikaido T, Takano Y, Sasafuchi Y, Burrow MF, Tagami J. Bond strengths to endodontically-treated teeth. Am J Dent. 1999;12:177-180.

44. Bojar W, Czarnecka B, Prylinski M, Walory J. Shear bond strength of epoxy resin-based endodontic sealers to bovine dentin after ozone application. Acta Bioeng Biomech. 2009;11:41-5

45. Shokouhinejad N, Sharifian MR, Jafari M, Sabeti MA. Push-out bond strength of Resilon/Epiphany self-etch and gutta-percha/AH26 after different irrigation protocols. Oral Surg Oral Med Oral Pathol Oral Radiol Endod. 2010;110:88-92.

46. Vilanova WV, Carvalho-Junior JR, Alfredo E, Sousa-Neto MD, Silva-Sousa YT. Effect of intracanal irrigants on the bond strength of epoxy resin-based and methacrylate resin-based sealers to root canal walls. Int Endod J. 2012; 45:42-48.

47. Zhou J, Tan J, Yang X, Cheng C, Wang X, Chen L. Effect of chlorhexidine application in a self-etching adhesive on the immediate resin-dentin bond strength. J Adhes Dent. 2010;12:27-31. 